\title{
ARTICLE
}

\section{Expectations of persons with paraplegia regarding their care in India: a qualitative study}

\author{
Nalina Gupta ${ }^{1}$ and Kavitha Raja ${ }^{2}$
}

\begin{abstract}
STUDY DESIGN: A qualitative study.
OBJECTIVE: The aim of this study was to understand expectations of persons with paraplegia in India regarding their care. SETTING: India.

METHODS: This study used a qualitative methodology to have a focus group interview of persons with paraplegia in India. Focus group consisted of two to four participants with paraplegia. Adults with level T6 and below, complete injury, duration of at least 6 months post injury and those living in the community were included. Online focus group interviews were conducted using ZOOM online software for online discussions/meetings. Data were collected till data saturation. Recorded videos were transcribed into texts, and the transcribed documents were analysed using the ATLASti.8 software for qualitative data analysis.

RESULTS: Forty-eight codes were retrieved under fourteen code groups. These code groups were acceptance, accessibility, advanced technology, assistive devices, basic skills, employment, expectations, experiences, functional independence, government policies, knowledge, psychological make-up, physiotherapy and rural area.

CONCLUSION: Because of lack of awareness, knowledge and education provided to persons with paraplegia, their expectations were often unrealistic. Patient education and education of the health professionals are two of the most important aspects in spinal cord injury rehabilitation that must be taken into consideration in India.
\end{abstract}

Spinal Cord Series and Cases (2017) 3, 17042; doi:10.1038/scsandc.2017.42; published online 13 July 2017

\section{INTRODUCTION}

Spinal cord injury $(\mathrm{SCl})$ is a devastating condition that leaves a healthy individual paralysed due to a traumatic injury. There is no national database on $\mathrm{SCl}$ in India, but the conservative estimate suggests incidence of $\mathrm{SCl}$ to be 20 per million. ${ }^{1}$

Patient-centred care has gained importance in health care. It has been reported that health-care providers must pay attention to patients' social and psychological aspects along with biomedical/diagnostic ones. He/she must be an active listener and should be ready to discuss issues raised by patients, as they may have varying degrees of expectations. ${ }^{2}$ Patients' expectations are an important predictor of their satisfaction. Patients' satisfaction has said to be achieved when their expectations have been met or exceeded. ${ }^{3}$

Expectation is anticipation or a belief a patient has regarding his/her health-care system. In general, expectations are based on cultural beliefs, education, awareness, socioeconomic status and each patient's understanding of his/her problem. There are two dimensions of the health-care system: objective/technological and subjective/qualitative. Though the attention paid is more on the former, the latter is also critical. Unmet expectations lead to dissatisfaction, disappointment, anger and noncompliance/ suboptimal compliance to the treatment and poor outcome. ${ }^{4}$

Expectations are generated based on personal characteristics, previous experience, role models, interaction with friends/ relatives, physiologic factors and sociocognitive factors. ${ }^{5}$ The Internet has an important role in generating expectations. ${ }^{6}$ It is very important to respect and respond to patients' knowledge, experiences and expectations. ${ }^{7}$ A health-care professional not only requires the technical knowledge or knowledge regarding a patient's condition but also needs to connect with the patient and understand what he/she expects. A biomedical model alone is insufficient to understand the patient, but we ought to use a biopsychosocial model to understand him/her completely. ${ }^{8}$ Studies on patients' expectations and $\mathrm{SCl}$ rehabilitation/paraplegia in India are scarce. Thus, the aim of the present study was to understand the expectations of persons with paraplegia regarding their care in India.

\section{MATERIALS AND METHODS}

This study was approved by the ethical committee registered under the Central Drugs Standard Control Organization in India. This study used a qualitative methodology using focus group interviews of patients with paraplegia in India. The focus groups consisted of two to four participants with paraplegia. Adults with level T6 and below, complete injury, a duration of at least 6 months post injury and those who were community dwellers were included in the study. We decided to take participants from the community and had the meetings online. We used ZOOM software ${ }^{9}$ for online discussion/meeting for the interviews.

Various organisations specialising in $\mathrm{SCl}$ rehabilitation were contacted for the details of participants falling under our inclusion criteria. List of names of persons with paraplegia was obtained from these organisations. Contact details of 52 participants were obtained. All of them were contacted telephonically to provide information regarding the study and to seek consent. We could not contact 8 individuals due to disturbance in telephone lines. Out of 44 participants, 20 participants were excluded due to nonavailability/busy schedule, having lesions at the cervical level or having no/poor network connection. After getting consent of 24 participants, demographic details were collected to ensure inclusion criteria. Information regarding the online interview was provided. Four

\footnotetext{
${ }^{1}$ School of Physiotherapy, RK University, Rajkot, India and ${ }^{2}$ JSS College of Physiotherapy, JSS University, Mysore, India. 
persons with paraplegia who did not have access to the Internet were contacted with the help of a local physiotherapist.

Once they gave their consent, an informal group was formed on WhatsApp to schedule interviews. Before the interview, participants were sent two forms related to their informed consent and demographic details. They were asked to fill those forms and send them before the interview. On the basis of participants' convenience, they were interviewed in small groups for an open-ended interview. There was no specific questionnaire, and topic outlines were used to facilitate the interview. Topics outlined were regarding their expectations of care after the injury, met/unmet expectations, information regarding their basic skills, daily tasks, community re-integration and their suggestions to improve the standards of care after $\mathrm{SCl}$ in India. Data were collected till data saturation (till no new information was obtained). Data got saturated after interviewing 20 subjects. Thus, after data saturation, we did not continue with the further interviews. Recorded interviews were transcribed into texts and analysed using ATLASti ${ }^{10}$ software for qualitative data analysis.

\section{RESULTS}

This study was an attempt to understand the expectations of persons with paraplegia regarding their care in India. In the beginning, efforts were made to invite $8-10$ participants at a time on ZOOM at a decided date and time, but we found difficulty because of their work schedules and nonavailability, as well as difficulty having a conversation with many participants at a time online. Thus, interviews were conducted in small groups till data saturation.

Demographic details of participants are as shown in Table 1. Forty-eight codes were retrieved from the transcribed documents using ATLASti and grouped under fourteen code groups. These code groups were acceptance, accessibility, advanced technology, assistive devices, basic skills, employment, expectations, experiences, functional independence, government policies, knowledge, psychological make-up, physiotherapy and rural area. Details of various codes, their code groups and quotations are as shown in Tables 2 and 3.

On the basis of these codes/code groups, we retrieved 20 points. It was sent to all the participants for 'participant checking'

\begin{tabular}{|c|c|c|}
\hline Demographic characteristics & Number (n) & Percentage (\%) \\
\hline \multicolumn{3}{|l|}{ Age (years) } \\
\hline $18-30$ & 11 & 55 \\
\hline $31-45$ & 06 & 30 \\
\hline $46-60$ & 03 & 15 \\
\hline \multicolumn{3}{|l|}{ Gender } \\
\hline Male & 17 & 85 \\
\hline Female & 03 & 15 \\
\hline \multicolumn{3}{|l|}{ Level of lesion } \\
\hline T6-T9 & 07 & 35 \\
\hline T10-T12 & 11 & 55 \\
\hline Lumbar & 02 & 10 \\
\hline \multicolumn{3}{|l|}{ Duration since injury (years) } \\
\hline$<1$ & 01 & 5 \\
\hline $1-5$ & 09 & 45 \\
\hline $6-10$ & 06 & 30 \\
\hline $11-15$ & 03 & 15 \\
\hline $16-20$ & & \\
\hline $21-25$ & & \\
\hline $26-30$ & 01 & 5 \\
\hline \multicolumn{3}{|l|}{ Employment } \\
\hline Yes/self-employed & 09 & 45 \\
\hline No & 06 & 30 \\
\hline Student & 05 & 25 \\
\hline
\end{tabular}

using google-form via email. In all, 14 participants responded and 3 of them added 1 point each, thus bringing the total to 23 points. A total of 6 nonrespondents were asked about their agreement telephonically. These 23 points are shown in Table 4 .

Table 2. Codes $(n=48)$ and code groups $(n=14)$

\begin{tabular}{|c|c|c|}
\hline S.no. & Code group & Codes \\
\hline 1 & Acceptance & $\begin{array}{l}\text { Acceptance } \\
\text { Realisation }\end{array}$ \\
\hline 2 & Accessibility & $\begin{array}{l}\text { Accessibility } \\
\text { Barrier-free environment } \\
\text { Transportation }\end{array}$ \\
\hline
\end{tabular}

$3 \quad$ Advanced technology Advanced technology

$4 \quad$ Assistive device Assistive device Availability of a good wheelchair Shifting board

5 Basic skills Skills

Improved skills transfers

6 Employment Employed Self-employed

$7 \quad$ Expectation

Expectation from physiotherapy Expectation from treatment Functional Independence Recovery Rehabilitation centre expectation Rehabilitation centres Specialised rehabilitation centres Unmet expectations

$8 \quad$ Experience

Experience with surgery First treatment Proper rehabilitation

9 Functional independence

Functional Independence

10 Government policies

Government should intervene Infrastructure

11 Knowledge Awareness Clarity

Education regarding condition Education regarding secondary complications and assistive devices Guidance for sports

Knowledge

Knowledge regarding rehabilitation Knowledge regarding shifting the patient

Knowledge regarding treatment Lack of knowledge Learning from peers Self-care education

12 Psychological Mindset make-up

Mindset

Positivity from peers Spiritual

13 Physiotherapy

Not able to continue physiotherapy Physiotherapy at home Physiotherapy experience Physiotherapy treatment

14 Rural area Life is spoiled for the one who stays in a village 
Table 3. Code groups and participants' quotations

\begin{tabular}{|c|c|c|}
\hline S. no. & Code group & Quotations \\
\hline 1 & Acceptance & $\begin{array}{l}\text { 'I had made up my mind that it will remain like this.' } \\
\text { 'In their classes, I had realised that I won't be able to walk as my spinal cord is cut.' }\end{array}$ \\
\hline 2 & Accessibility & $\begin{array}{l}\text { 'We really need to think a hundred times whether to go or not. Just we are stuck in closed room.' } \\
\text { 'If we have to go to a bank, we get stairs. There are no ramps. Even in railway stations, there are stairs, and no } \\
\text { ramps. It's a big problem.' } \\
\text { 'Four persons lift us with a wheel-chair and there is a risk that wheels of the chair may come out and may } \\
\text { increase our injury.' }\end{array}$ \\
\hline 3 & Advanced technology & $\begin{array}{l}\text { 'Whatever things are coming on } \mathrm{SCl} \text { like stem cell, brain cell stimulation, even if we want to get it done, we } \\
\text { cannot do it as it is costly and there is no surety.' }\end{array}$ \\
\hline 4 & Assistive device & $\begin{array}{l}\text { 'Wheel chair is the biggest problem. The one we have is old and our financial status is not like that we can buy } \\
\text { new one. We don't know when tyres will come out.' } \\
\text { 'Whenever NGOs give wheel-chair, it should be of good quality, not for name-sake' }\end{array}$ \\
\hline 5 & Basic skills & $\begin{array}{l}\text { 'I have learnt transfers from myself. My friend used to come and told me about shifting and movement and then } \\
\text { I practised.' } \\
\text { 'Its' like I have to live with this and I learnt.' }\end{array}$ \\
\hline 6 & Employment & $\begin{array}{l}\text { 'They were giving me options but I did not like that much. Also, I felt that this will occupy more time and I won't } \\
\text { have much time for physiotherapy. So, I opted to resign.' }\end{array}$ \\
\hline 7 & Expectation & $\begin{array}{l}\text { 'I had lots of expectations but they have not been fulfilled.' } \\
\text { 'Due to lack of knowledge, our expectations were not realistic /practical.' } \\
\text { 'I had a complete idea, so I did not keep much hope to it.' } \\
\text { 'We used to have meeting with doctors and staff about our improvement and treatment goal. I used to tell them } \\
\text { to make me stand on my feet. I feel that they have done cheating.' }\end{array}$ \\
\hline 8 & Experience & $\begin{array}{l}\text { 'The person, who lifted me, made me sit first and then lifted me. When I told this to my doctor, he told me that } \\
\text { this may have increased the injury.' } \\
\text { 'By God's grace, I was fortunate to reach a good hospital.' } \\
\text { 'I did not get good first treatment as it is not that known here. They made me lie on bed for one month and I had } \\
\text { pressure sores. They did not even operate me.' } \\
\text { 'I feel that my surgery did not go well. I should not have gone for surgery. They have cut my back for 6-7 inches. } \\
\text { My surgery should have been at the level of injury, my incision is of 6-7 inches.' }\end{array}$ \\
\hline
\end{tabular}

9 Functional independence 'It is very important for persons with paraplegia to do all their work by themselves.'

10 Government policies

11 Knowledge

12 Psychological make-up

13 Physiotherapy

\section{'Government should intervene and improve the infrasturctures'}

'We didn't know what $\mathrm{SCl}$ is, this subject is new for us.' 'Doctors did not tell me about rehabilitation whether I should do it or not. They did not tell how to care for ourselves. They should atleast tell us what it is.' 'People are stuck in their four walls as they don't have knowledge.' 'In my rehabilitation centre, actually I was able to know the complete scope of my injury... like how will I recover, whether i will recover or how long I will take to recover.'

'People have this mind-set that they will be able to walk like before but that does not happen.' 'What to say... there is no end to dreams. God knows when that day will come that we will leave wheel-chair and stand. We don't know when God has written that day.'

'I come from a place where there is no scope of physiotherapy. But my physiotherapist has done a lot for me.' 'After coming back from the rehabilitation centre, no therapist has a proper knowledge for regular exercise. They used to behave as if they have not seen such cases. I had to tell them that I was made to do like this in a specialised centre.'

'Physiotherapy centre is little far from here, around 1.5-2 km from here. After coming back from college, we cannot go there as we are really tired. If we get it in hostel, we can do that. Otherwise we cannot do that.'

14 Rural area
'Life gets spoilt for the ones who stay in a village.'

Abbreviations: NGO, non-government organisation; SCl, spinal cord injury.

\section{DISCUSSION}

Most of the participants interviewed did not have any knowledge regarding $\mathrm{SCl}$ before the injury. Most of them did not know about their prognosis even after the injury. Patients who were treated in specialised centres had better ideas/knowledge about their condition, hence were more comfortable with their present situation. Alternatively, they had higher expectations from rehabilitation professionals, which often led to disappointment if the rehabilitation at their local areas (nonspecialised centres) did not meet with their expectations.

Lack of knowledge of $\mathrm{SCl}$ leads to unrealistic expectations, inappropriate ways of lifting and shifting the victim from the site 
Table 4. Content after 'participant checking'

1. General public is not aware of $\mathrm{SCl}$

2. Knowledge regarding $\mathrm{SCl}$ is lacking

3. Knowledge regarding transportation of spinal cord-injured person is lacking

4. Initial/first treatment after $\mathrm{SCl}$ is not good at all places, especially at nonspecialised centres and/or centres in rural areas

5. There is lack of knowledge regarding physiotherapy care after $\mathrm{SCl}$

6. There is lack of information provided by the health-care practitioner of recovery after SCl; thus, there is no clarity of prognosis/recovery

7. Walking is the main expectation after $\mathrm{SCl}$, especially without any help, on both the feet along with self-dependence, transfers and decrease in stiffness

8. Physiotherapy training is not adequate at nonspecialised centres and/or centres in rural areas and/or given at home

9. Skills such as bed mobility, transfers and wheelchair ambulation were gained from friends/oneself in many cases

10. Education regarding assistive technology such as wheelchair/orthosis/walking aids was not given at all the centres

11. Education regarding care at home and that of secondary complications such as pain, stiffness was not provided by all physiotherapists/in all the centres

12. Environment outside is not wheelchair-friendly/barrier-free

13. Government should take measures to improve infrastructures and standards of care after $\mathrm{SCl}$ in India

14. Functional independence is very important, a person with paraplegia must try to do all the activities by himself/herself

15. Physiotherapy must be started from an early stage

16. Skills obtained sooner post injury will help with regaining earlier functional independence

17. There must be continuous assessment and follow-up by a concerned therapist

18. Many a times, physiotherapy treatment is not continued due to financial constraints

19. Expectations regarding health care are not completely met in many cases

20. Advanced technologies like stem cells, brain stimulation, robotics and so on are costly, and their success rate is unknown

21. People should stop staring at individuals with $\mathrm{SCl}$ as if they are aliens

22. Knowledge must be given regarding treatment after discharge from the hospital

23. State government should help individuals with obtaining employment

Abbreviation: SCl, spinal cord injury.

of accident, and that may in turn worsen the condition. Awareness regarding $\mathrm{SCl}$ will help in minimising the consequences. ${ }^{11}$ Thus, there is a need to increase awareness among general population, caregivers, patients, clinical and paraclinical staff regarding $\mathrm{SCl}$ in India. ${ }^{12}$ On the basis of this motto, 5 September 2016 was celebrated as a World Spinal Cord Injury Day, an initiative of the International Spinal Cord Society, and it was supported in India too. ${ }^{13}$

Safe transportation of the $\mathrm{SCl}$ victim must be stressed, as persons with $\mathrm{SCl}$ are often shifted by persons who have no knowledge regarding safe transportation and that leads to neurological deterioration. ${ }^{12}$ There are disparities in emergency care delivery or immobilising the spine at the site of accident between developed and developing countries. In low-resourced countries, it is rare to see a victim stabilised and transported by trained personnel. ${ }^{14}$ It has been suggested in one of the studies that policemen must also be trained along with paramedical in stabilising the spine and maintaining the airways, as they are the first ones to reach the site of accidents in India, as has already been implemented in Mumbai, India. ${ }^{15}$ It was also stressed that these individuals must be transferred to tertiary spinal care centres as soon as possible. ${ }^{12}$

Educating patients and their families regarding injury, prognosis and complications is very important. They are more prone to develop secondary complications if not taken care of properly; hence, continuous health care is important. Timely treatment and education of persons with $\mathrm{SCls}$ is often unavailable in lessdeveloped countries like India due to a lack of specialised centres, untrained personnel, lack of equipment and a multidisciplinary approach. ${ }^{16}$ It is also challenging to counsel individuals with $\mathrm{SCl}$ regarding the nature of injury and its prognosis due to cultural settings in developing countries. In the beginning, they are reluctant to accept the fact and try to seek spiritual and faith healers. $^{17}$

Every individual's needs are different and so are their preferences. ${ }^{18}$ Hence, it is important for a rehabilitation professional to be sensitised and empathetic towards the patient's expectations. ${ }^{19}$ Advanced technology, no doubt, raises expectations, but the patient needs to be educated for the same. ${ }^{18}$
In developing countries, there are no peer counsellors in all hospitals. Hence, it has been emphasised that every professional of the rehabilitation team must be involved in educating the person with $\mathrm{SCl}^{19}$ For maintaining long-term health and follow-up care, it has been recommended that each health-care team must visit persons with $\mathrm{SCl}$ in their community like that of Paraplegia Safari (a follow-up programme/home-visit programme for persons with $\mathrm{SCl}$ ) in India. ${ }^{20}$

In our study, most of the persons with paraplegia either had learned basic skills such as bed mobility, transfers and independent wheelchair ambulation by themselves or from their friends. Although our study can be considered biased because all participants had internet access, availability of a good wheelchair or a customised one was an issue. Physiotherapy-assisted transfers, wheelchair skills or even postural training for individuals with $\mathrm{SCl}$ are lacking in local centres/nonspecialised centres. ${ }^{16}$ Hand-rim-propelled wheelchairs observed in one of the studies in India were very heavy and nonadjustable. Many individuals were encountered who required wheelchairs but did not have them. ${ }^{19}$ Assistive technology has been reported to be an issue in low- and middle-income countries. Persons with $\mathrm{SCl}$ may have unmet needs of assistive technology even in high-income countries. Attitudes such as 'something is better than nothing' and 'one size fits all' are normally used in less-resourced countries. Inadequate user's need for assessment and low user involvement in decision making are some of the reasons for inappropriate wheelchairs that could have negative consequences. ${ }^{19}$

After $\mathrm{SCl}$, there is lower return to work rate because either the person does not go back to his/her pre-SCl work status or he/she may not be hired. However, there are available rights of employees in India that they should be made aware of. ${ }^{16}$ Lower return to work rate could be due to inaccessibility, transportation issues and lack of disability-related accommodations at work site. ${ }^{20}$ Flexible working hours and job sharing are some of the programmes being encouraged by government in some countries. ${ }^{21}$ There is a need to encourage job accomodations for these individuals. ${ }^{15}$ Telework, working at a remote place using technologies, may be an option for persons with $\mathrm{SCl}$ in India and 
could help overcome issues of accessibility, transportation and health limitations. ${ }^{21}$

Educational participation must be enhanced, and there should be strategies to overcome accessibility issues. At the same time, education and rehabilitation must be brought together. ${ }^{21}$ One of the important barriers for their exclusion from full participation in the society is negative attitudes of an unaware society. ${ }^{16}$

\section{CONCLUSION}

Because of lack of awareness and education provided to persons with paraplegia, many times expectations are not realistic/practical. Patient education and education of the health professionals are two of the most important aspects in $\mathrm{SCl}$ rehabilitation that must be taken into consideration in India.

\section{Implication}

There is a need to create awareness of $\mathrm{SCl}$ and shifting of a victim with $\mathrm{SCl}$ from the site of accident in India. ${ }^{7,8}$ Hoardings (a large board in a public place to display), pamphlets or use of media to create awareness and knowledge regarding $\mathrm{SCl}$, its prevention and transportation of spinal cord-injured victim are few of the measures that could be adapted. ${ }^{12}$ There is a need to provide clarity about patients' recovery or prognosis, so that they do not have unrealistic expectations. ${ }^{3}$ Patient education and education of the health professionals are two of the most important aspects of $\mathrm{SCl}$ rehabilitation. E-learning resources ${ }^{20,21}$ can be tried for their feasibility in India. Rehabilitation professionals must have knowledge regarding various organisations dealing with wheelchairs in India, so that mobility of persons with paraplegia is not hampered.

\section{ACKNOWLEDGEMENTS}

We thank all our participants for giving their consent to participate in the study and for sharing their experiences/expectations regarding their care post injury. We acknowledge Dr Ketna Mehta, Ms Shazia Mattu, Mr Eishan Aggrawal, Mr Rashmikant, Mr Harsh Omer and Mr Kiranjani for providing the details of persons with paraplegia living in the community.

\section{COMPETING INTERESTS}

The authors declare no conflict of interest.

\section{REFERENCES}

1 Dhar A. The government plans three specialised spinal injuries centres to aid people with locomotor disabilities. Health-Few Steps Forward. The Hindu. 2013. Available at http://www.thehindu.com/sci-tech/health/few-steps-forward/arti cle4978239.ece.

2 Potter M, Gordon S, Hamer P. The physiotherapy experience in private practice: the patients' perspective. Aust J Physiother 2003; 49: 195-202.

3 McKinley RK, Stevenson K, Adams S, Manku-Scott TK. Meeting patients' expectations of care: the major determinant of satisfaction with out-of-hours primary medical care? Fam Pract 2002; 19: 333-338.

4 Lateef F. Patient expectation and the paradigm shift of care in emergency medicine. J Emerg Trauma Shock 2011; 4: 163-167.

5 Bowling A, Rowe G, Lambert N, Waddington M, Mahtani KR, Kenten C et al. The measurement of patients' expectations for health care: a review and psychometric properties of a measure of patients' expectations. Health Technol Assess 2012; 16: 1-532.

6 Broom AF. The influence of internet on patients' expectations. Nat Clin Pract Urol 2006; 3: 117.

7 Trylinska-Tekielska E. Questionnaire of expectation patient-physiotherapist (QEPP). Adv Pall Med 2012; 11: 56-61.

8 Löfgren M, Norrbrink C. 'But I know what works'-patients' experience of spinal cord injury neuropathic pain management. Disabili Rehabil 2012; 34: 2139-2147.

9 ZOOM (Web \& Video Conferencing) What, Why and How. Campus Health. Available at https://www.zoom.us/.

10 ATLAS.ti 8. The Next Level. ATLAS ti: The Qualitative Data Analysis \& Research Software. Available at http://www.atlasti.com.

11 Sridharan N, Uvaraj NR, Dhanagopal M, Gopinath NR, Anuswedha A. International Journal of Research in Medical. Sciences 2015; 3: 220-223.

12 Pandey VK, Nigam V, Goyal TD, Chhabra HS. Care of post-traumatic spinal cord injury patients in India: an analysis. Indian J Orthop 2007; 41: 295-299.

13 World Spinal Cord Injury Day. Available at http://www.worldsciday.org.

14 Burns AS, O'Connell C. The challenge of spinal cord injury care in the developing world. J Spinal Cord Med 2012; 35: 3-8.

15 Srinivasan US. Acute spinal cord injury: managing at the site of impact and addressing reality gap. J Assoc Physicians India 2012; 60(Suppl): 7-9.

16 Chhabra HS, Batra S. Spinal cord injury and its impact on the patient, family and the society. Int J Recent Surg Med Sci 2016; 2: 1-4.

17 Harvey LA. Physiotherapy rehabilitation for people with spinal cord injuries. J Physiother 2016; 62: 4-11.

18 International Perspectives on Spinal Cord Injury. World Health Organisation and International Spinal Cord Society, 2013. Available at http://www.iscos.org.uk// international-perspectives-on-spinal-cord-injury.

19 Kerby RL, Cooper RA. Applicability of the wheel-chair skills program to the indian context. Disabil Rehabil 2007; 29: 15-30.

20 Shepherd JD, Badger-Brown KM, Wolfe DL. SCI-U: E-learning for patient education in spinal cord injury rehabilitation. J Spinal Cord Med 2012; 35: 319-329.

21 Chabbra HS. Spinal cord-www.elearnSCl.org: a global educational initiative of ISCoS. Spinal Cord 2013; 51: 176-182. 